\title{
دراسة إقتصادية لإنتاج محصول المورنجا فى الأراضي الجديدة
}

\section{محمد على عواد أبو النجا}

قسم الدراسات الاقتصادية- شعبة قسم الدراسات الاقتصادية والاجتماعية- مركز بحوث الصحراء

Received: May 12, 2016

Accepted : Jun. 16,2016

الملخص

إستهذف البحث دراسة التحليل المالي والإقتصادي لزراعة محصول المورنجا ببنطقة وادى النطرون، للتعرف على مدى النى

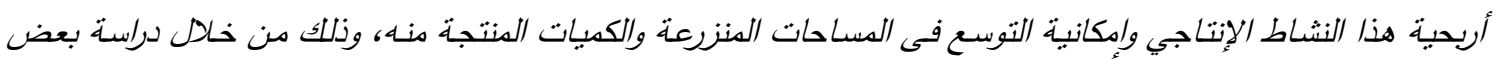

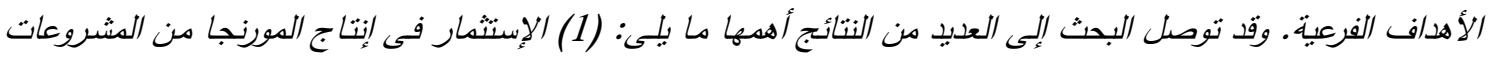

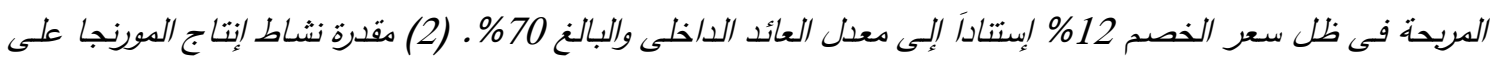

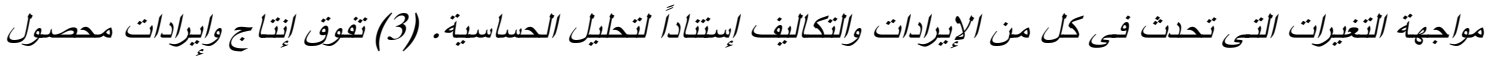

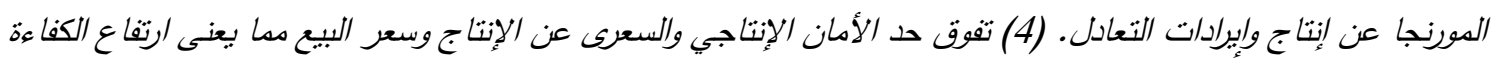

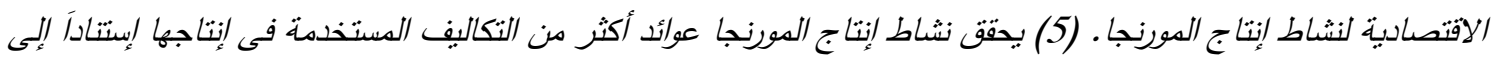

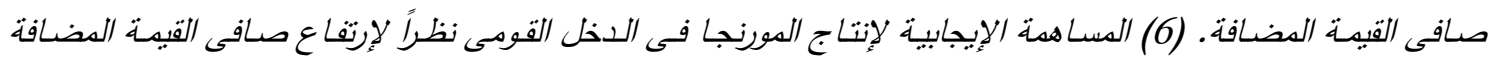

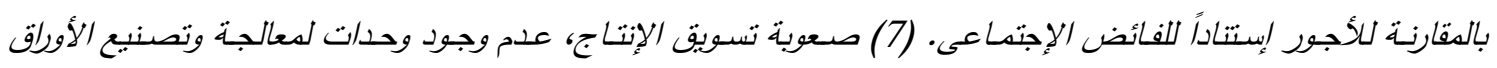
والبذور وعدم توافر مصادر موثوق بها للحصول على الشتلات كانت أهم المشكلات التى تواجة منتجى المورنجا بمنطقة

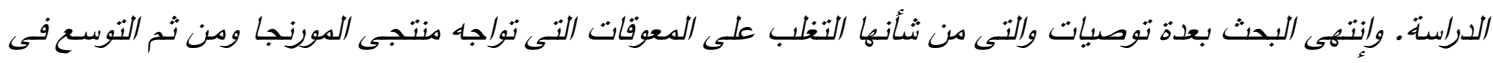
زراعة هذا الدحصول والنهوض بإنتاجيته.

الكلمات الإفتتاحية: الدورنجا، النكاليف، العائد، التحليل المالي، التحليل الإقتصادى، الأراضي الجديدة، وادي النطرون.

فى حديقة الأورمان بالقاهرة تصدر بذورها لكثير من دول

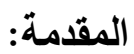

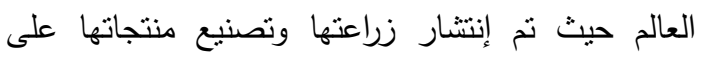
تعتبر أثنجار المورنجا(7) من النباتات شبه الإستوائية مستوى العالم.

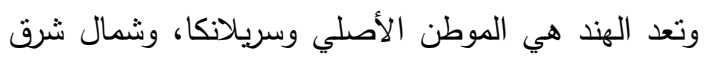

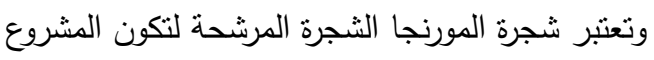

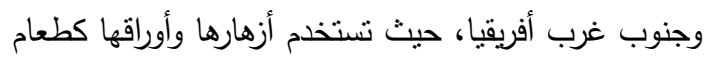
الزراعى الإنتاجي على المستوى القومى القادرة على تحقيق وفى التناوي. وهي معروفة أيضاً في السودان وقد انتشرت أندان نجاحات هائلة ومكاسب مربحة للكثير من المستثمرين، الكئل أثجار المورنجا لظلّها الوفير في جنوب التوب مصر وشمال ومشاركة بقوة فى تحقيق الأمن الصناعي والغذائي السودان وفي المنطقة الغربية بالمملكة العربية السعودية. والمائي، لقدرتها الهائلة على النمو والإثمار والبقاء منتجة الأنة وفي الفلبين بستخرج من جذورها مادة دوائية طاردة للايدان

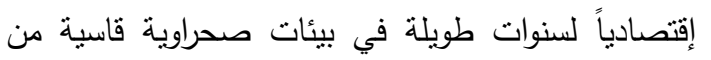

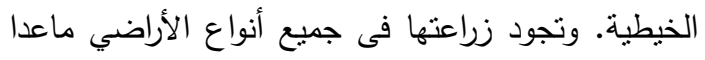
حيث إرتفاع وإنخفاض درجة الحرارة، وإستخدام الأراضي لاضي

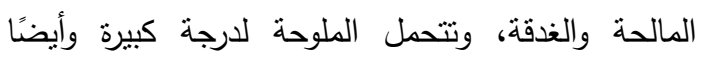
الهامشية التي لا تدعم المزيد من الدحاصيل الثقليدية،

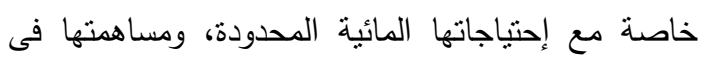
الجفاف وتجود زراعتها فى مصر خاصة فى الصعيد والأراضي الجديدة ومنطقة سيناء، ويوجد منها عدة أثنجار 
وخاصة بالأراضي الجديدة والتي من أهمها نوافر الموارد

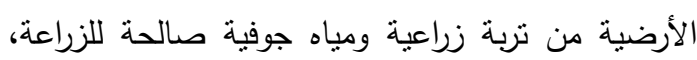
وملائمة كافة الظروف البيئية بها للتوسع في زراعة ورإنتاج

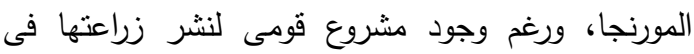

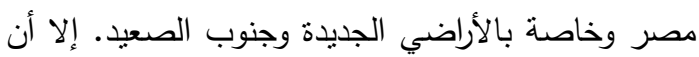

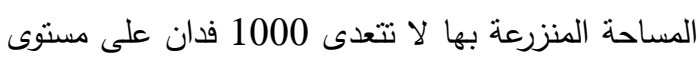
الجمهورية(5)، مما يدل على عدم وجود دراسات إقتصادية

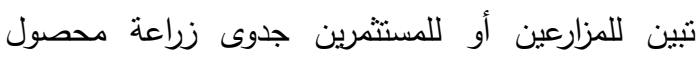
المورنجا، ووجود مشكلات إنتاجية وتسويقية تواجه منتجى

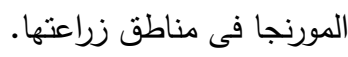

\section{أهداف البحث: إستهدف البحث بصفة أساسية دراسة} التحليل المالي والإقتصادي لزراعة محصول المورنجا

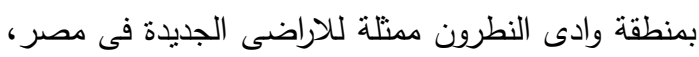

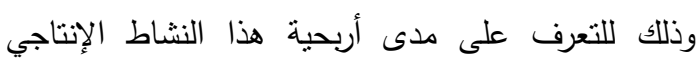
وإمكانية التوسع فى المساحات المنزرعة وزيادة الكميات المنتجة من المورنجا، وذلك من خلال دراسة الأهداف الفرعية التالية: (1) التعرف على على المزايا والأهمية الإقتصادية لزراعة المورنجا. (2) دراسة التوزيع الجغرافي لمحصول المورنجا على مستوي الجمهورية. (3) قياس نقطة التعادل الكمى للإنتاج والإيرادات وتقدير مدئ حد الأمان المطلوب لهذا النشاط. (4) تقدير معايير التقيبم المالي لفئي والإقتصادي لزراعة محصول المورنجا بمنطقة الدراسة

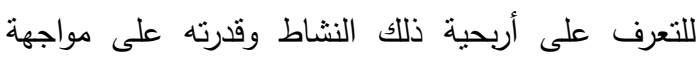
التغيرات التي قد تحدث في كل من التكاليف والإيرادات. (5) دراسة وتحليل المشاكل التى نواجه منتجى المورنجا بعينة الدراسة ومقترحات حلها.

أسلوب البحث: إعتمد البحث لتحقيق أهدافه على أسلوب التحليل الإحصائي الوصفي والكمي للبيانات، والإستعانة ببرنامج Cost Benefit Analysis والذي الإئي يعتد على إستخدام معايير التحليل المالي والإقتصادي

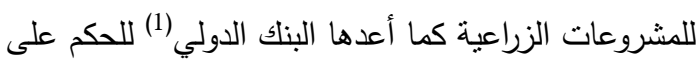

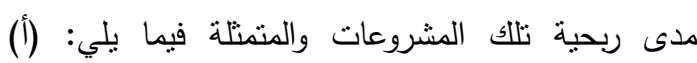

تحسين نوعية العياه والتزبة. إضافة لقيمتها الغذائية وإمكانياتها الطبية التى جعلتها تستخدم فى حضارات مصر الفرعونية كمصدر غذائي وزيت للطعام وفى صنع الأدوية والعطور ومستحضرات التجميل. حيث انتشرت شجرة المورنجا وزرعت بواسطة قدماء المصريين وفى الهند من آلاف السنيين. ومن ثم تعتبر شجرة المورنجا من أهم

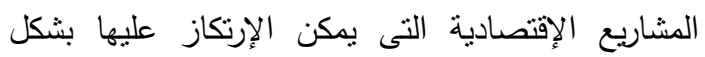

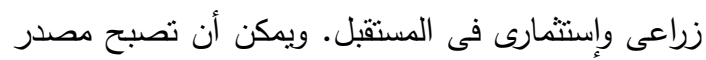

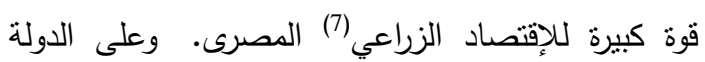

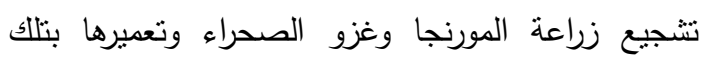
النباتات التي لها عائد إقتصادي مناسبا. ومزو وتعتبـــر منطقـــة وادى النطـــرون إحــــى منـــاطق

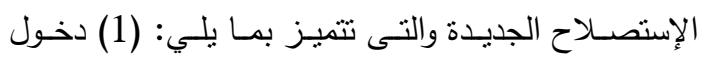
الأراضي بها مراحل الإنتاج الوفير منذ فترة طويلة نسبياً.

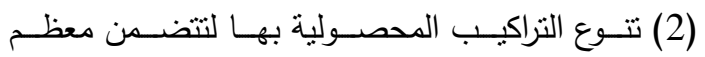
المحاصيل الحقلية والغير تقليديـة والخضر والفاكهة. (3) بلتهن

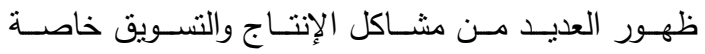
للحاصلات الغير نقليدية كالمورنجا بتلك المنطقة.

أهمية البحث: يستمد البحث أهميته من الأهمية

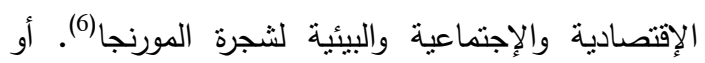

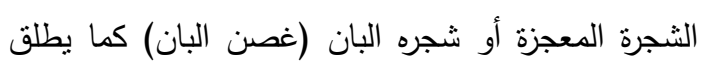

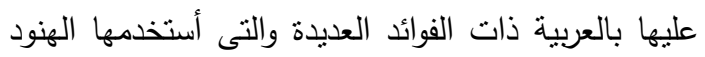

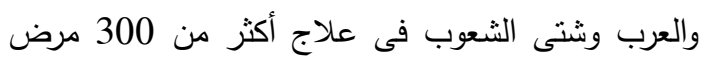

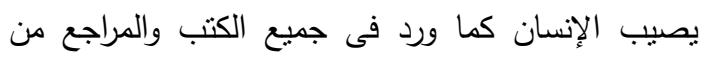
تذكرة داوود الأنطاكى، حتى فى عهدنا الحديث ما تحدث كتاب عن الطب البديل والعلاج بالأعشاب إلا وذكر فيها جزء من نبات المورنجا سواء أوراق أو زهور أو قلف أو أو الوكي خشب أو بذور وحتى جذور الثجرة المتعقة فى التربة. مشكلة البحث: على الرغم من الأهمية الإقتصادية والإجتماعية والبيئية لأشجار المورنجا، وتوافر العديد من الإنية الإنهاتيه الإمكانات الهائلة التي تمنلكها جمهورية مصر العربية الإئة 


\section{An economic study for production of moringa crop in the new landes}

العينة من 10 مزارع مورنجا تمتل نحو 100\% من إجمالي عدد مزارع ومساحة المورنجا في منطقة وادي

النطرون بمحافظة البحيرة نم دراستها بالحصر الثامل.

$$
\text { نتائســـج الدراسة: }
$$

أولاً: الأهمية الاقتصادية والإجتماعية والبيئية للمورنجا:

للمورنجا أهمية ومنزلة خاصة ذات أبعاد إقتصادية وإجماعية وبيئية. تكمن الأهمية الإقتصادية للمورنجا بالدور المستقبلى الذى يمكن أن تلعبه بالمساهمة في الناتج الأنجادية

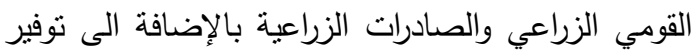
مدخلات الإنتاج لبعض الصناعات منل الصناعات الغذائية، ومعالجة المياه والأعلاف ومخصبات التربة. حيث تزرع المورنجا إما لإنتاج الأوراق أو البذور أو لكلا والاه الغرضين لتلبية جزء من المتطلبات الغذائية والتصنيعية للسكان فى مناطق زراعتها، يضاف الى ذلك قيمتها الغذائية، فقد أوضحت الدراسات(9) أن الأوراق الطازجة

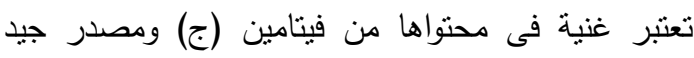
لفيتامين (ب) والعناصر المعدنية خاصة الكالسيوم كما فيا تحتوى على بروتين، كما أنها غنية فى محتواها من العنانية البوتاسيوم. كما تتميز أوراق المورنجا بإحتوائها على نسبة عالية من عنصر الحديد لذلك فهى تستخدم فى علاج

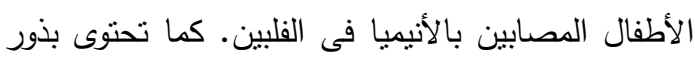

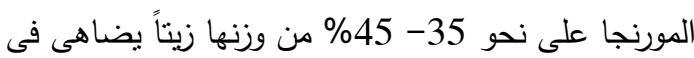
جودنه زيت الزيتون بل ويتميز عنه بصلاحيته للإستخدام الآدامى ولفترات طويلة تصل الى 5 سنوات دون تزنخ، بالإضافة إلى أن زيت المورنجا له أهية كبيرة فى صنات صناعة لهن مستحضرات التجميل وخاصة إزالة التجاعيد وآنار التقدم فى العمر وكذلك مستحضرات العناية بالشعر والجلد

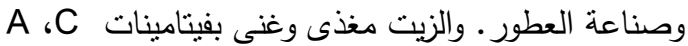
ومجموعة من الأحماض الدهنية غير المشبعة، وله خصائص مطهرة ومضادة للالتهابات ويساعد على إلتئام الجلد، ويستخدم للوقاية وعلاج لدغات الحشرات ومفيد فى
معايير التحليل المالي غير المخصومة وهى المعايير التي

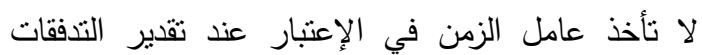

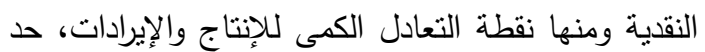
الأمان الإنتاجى والسعرى. (ب) معايير التحليل المالي

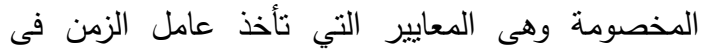
الإعتبار عند تقدير التذفقات النقدية ومنها صافى القيمة الحالية للتدقات النقدية ومعدل العائد الداخلي ونسبة المنافع إلى التكاليف وفترة إسترداد رأس المال، بالإضافة إلى تحليل الحساسية للتعرف على مدى قدرة المشروع على تحمل التغيرات السعرية التي تطرأ على عناصر التكاليف والإيرادات. (ج) معايير التحليل الاقتصادي وهى معايير تستخدم لقياس وتقييم الآتار الكلية للمشروع طوال عمره الافتراضي بإستخدام سعر الخصم للإيرادات والتكاليف بالأسعار الاقتصادية ومنها القيمة المضافة، صافى القيمة المضافة والفائض الاجتماعي.

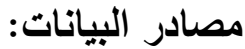
إعتمد البحث على البيانات الثنانوية التي تصدرها الجهات ذات الصلة مثل وزارة الزراعة وإستصلاح الأراضي، الجهاز المركزي للتعبئة العامة والإحصاء، الثركة المصرية للزيوت الطبيعية، الثبكة الدولية للمعلومات (الإنترنت)، المركز القومى للبحوث، الجمعية العلمية المصرية للمورنجا، مديرية الزراعة بمديرية التحرير

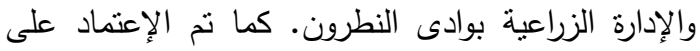
الكتب والنشرات والدجلات والدراسات السابقة المنشورة وغير المنشورة ذات الصلة بموضوع الدراسة والتي تصدرها الجهات والمؤسسات العلمية كمصدر أول للبيانات. بالإضافة إلى البيانات الميدانية والتي تم الحصول عليها من خلال إستمارة إستبيان تضمنت كافة المتغيرات اللازمة لتحقيق أهداف الدراسة لعينة مزارع المورنجا بمنطقة وادى النطرون بمحافظة البحيرة خلا عام 2015/2014، حيث بلغت مساحة(8) المورنجا بها نحو 50 فدان تمثل عام نحو 62.5\%، 5\%، من إجمالى مساحة المورنجا على

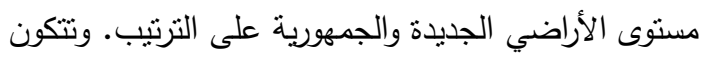




\section{Abo Elnaga}

2-تزرع بنجاح على جسور الترع والمجارى المائية وبالحدائق المنزلية والثقاسيم وحول المزارع. 3- تستخدم فى تحسين خواص التربة.

4- تستخدم فى عدة مجالات أخرى منل مكافحة النيماتودا وتغذية الحيوانات وتربية النحل الى جانب إمكانية إستخدام كافة معطيات الأشجار فى الدواء والعلاج. 5- لم تسجل إصابتها بالآفات والأمراض إلا إذا لأناء زرعت تحت ظروف غير مناسبة متل الزراعة بالأماكن

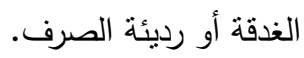

6- تحنوى على أغلب العناصر التى يحتاجها جسم الانسان وتعتىى بالصحة وتعتبر سلاح ناجح ضد سوء لئاه

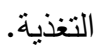

\section{(ب): إستخدامات المورنجا} 1- أزهارها وثمارها تستخدم فى أغراض الزينة. 2- مسحوق البذور يستخدم فى نرويق الياه العكرة لإحتوائه على مركبات زيتية لها القدرة على تجميع وترسيب المواد العالقة بالماء فيصير رائقاً وصالحاً

$$
\text { للشرب. }
$$

3- تستخدم فى صناعة العطور ومستحضرات التجميل لقدرتها على تثبيت بعض المكونات الطيارة فى هذه

$$
\text { المستحضرات. }
$$

4- أوراق المورنجا من أفضل الخضراوات التى تعتبر أحد

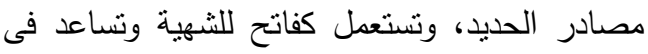
عملية الهضم. 5- تحتوى بذور المورنجا على نحو 35- 45\% من

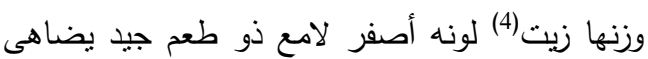
من حيث الجودة زيت الزيتون، ويحترق بدون دخان، ويمتاز بفترة صلاحية طويلة الامد تصل لحوالي 5

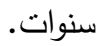
6- نستخدم لإنتاج العسل حيث يتغذى النحل على رحيق

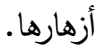
7- يستخدم القلف فى دباغة الجلود. 8- تستخدم على هيئة بهارات.
حالات الأمراض الجلدة. ويدخل الزيت فى إنتاج الوقود الحيوي للماكينات وفى صناعة زيوت تشحيم المحركات.

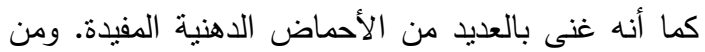
ثم يمكن لأشجار المورنجا أن تصبح مصدر قوة كبيرة للإقتصاد الزراعي وعلى الدولة نتجيع زراعتها وغزو الصحراء وتعميرها بتلك النباتات التي لها عائد اقتصادي لتراعيا

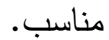
بينما تتمتل الأهمية الإجتماعية للمورنجا في إعتماد شريحة كبيرة من الأسر الريفية على هذا القطاع بشكل

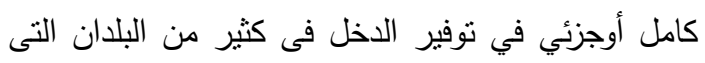
تقوم بزراعتها، حيث يوفر هذا القطاع فرصاً للعمالة واستغلالاً لطاقات بعض افراد أسر المنتجين غير المستغلة مما يساعد على الحد من البطالة.

وتتمثل الأهمية البيئية التي يمكن أن تحظى بها المورنجا في حماية التربة من الإنجراف والحد من عملية التصحر، فلأشجار المورنجا القدرة على النمو والإثمار والبقاء منتجة إقتصادياً لسنوات طويلة في بيئات صحراوية

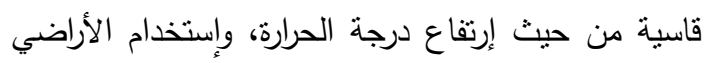
الهامشية التي لا تدعم المزيد من الهحاصيل التقليدية

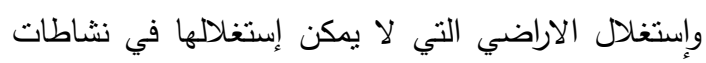
أخرى كالأراضي الوعرة والأراضي شبه الجافة والمنحدرات،

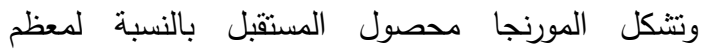
الأراضي شبه الصحراوية إذا ما تم توفير الإحتياجات الموردية له ونشر الوعى لاى صغار الدنتجين والمستثرين بالمردود الإقتصادى لهذا المحصول للزراعة.

\section{1 - فوائد ومزايا زراعة المورنجا}

تتعدد فوائد ومزايا زراعة المورنجا حيث يمكن الاستفادة

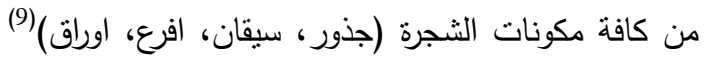
وفى إستخدامات عديدة:

(أ): خصائص ومميزات أثجار المورنجا 1- إحتباجاتها المائية محدودة جداً حيث تجود زراعتها على معدلات أمطار 300- 400 مم/ سنة. 
الجديــ 12\%، الفيـوم 12\%، سوهاج 8\%، \%، الإنسماعيلية

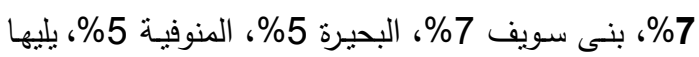
شبة جزيرة سيناء 4\%، ومحافظات أسيوط، الثرقية، البحيرة،

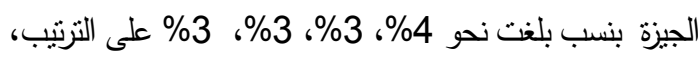

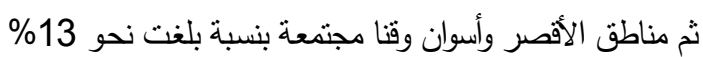
من إجمالى مساحة المورنجا على مستولى الجمهورية. ثالثاً: الملامح الإقتصادية لإنتاج المورنجا: يعد العائد

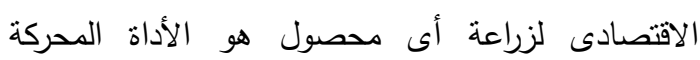

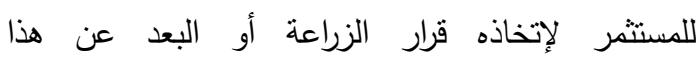
المحصول، وذلك بدراسة بنود التكاليف الثابتة والمتغيرة وبنود الإيراد السنوى خلال فنزة الدراسة(2)، وسيتم تناول

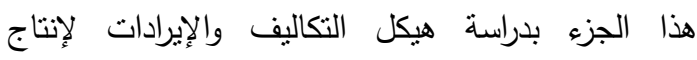
المورنجا بعينة البحث بمنطقة وادى النطرون خلال عام

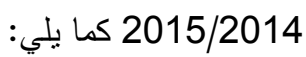

9- ثمار بعض الأنواع تؤكل منل الفول الأخضر ولكن

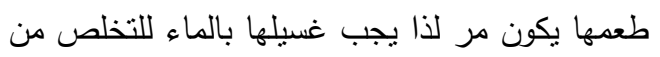

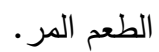
10- تستخدم كأثجار للزينة والظل وإنتاج حطب الوقود. 11- خشب الثجرة طرى والفحم المنتج منه جيد. 12- تعتبر علف ممتاز مقارنةً بالبرسيم الحجازى. 13- ينتج منها كسب جيد بعد عصر الزيت من البذور بستخدم فى تتقية مياه الثرب بدلا من إستعمال الكيماويات.

ثانيـاً: التوزيـع الجغرافي لمحصسول الموزنجـا في مصر خلا ألفترة (2013 - 2015)

يتبين من جدول (1) الذى يشير إلى التوزيع الجغرافي

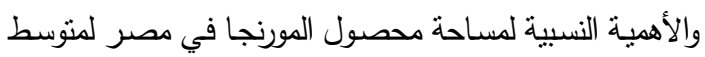
ألفترة (2013 - 2015)، أن إجمـالى المســاحة المنزرعـة

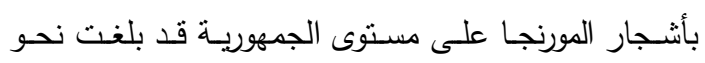

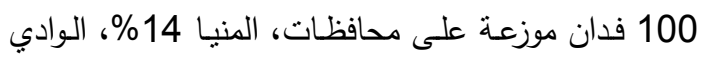

جلول رقم (1): التوزيع الجغرافي لمساحات محصول المورنجا في مصر لمتوسط ألفترة (2013 - 2015)

\begin{tabular}{|c|c|c|c|c|c|}
\hline$\%$ & المساحة (فدان) & المحافظة & $\%$ & المساحة (فدان) & المحافظة \\
\hline 12 & 120 & الفيوم & 5 & 50 & البحيرة \\
\hline 14 & 140 & المنيا & 3 & 30 & الثرقية \\
\hline 4 & 40 & أسيوط & 3 & 30 & الإسكندرية \\
\hline 8 & 80 & سوهاج & 5 & 50 & المنوفية \\
\hline 13 & 130 & قنا والأقصر وأسوان & 7 & 70 & الإسماعيلية \\
\hline 4 & 40 & شبة جزيرة سيناء & 3 & 30 & الجيزة \\
\hline 12 & 120 & الوادى الجديد & 7 & 70 & بنى سويف \\
\hline 100 & 1000 & \multicolumn{4}{|c|}{ إجمالى الجمهورية } \\
\hline
\end{tabular}

المصدر: جمعت وحسبت من: المركز القومى للبحوث، الجمعية العلمية المصرية للمورنجا، بيانات غبر منشورة 2015. 


\section{Abo Elnaga}

بلغت نحو 4000، 4750، 3500، 1000،

300 جنيه تمنل نحو 9\%، 26.85\%، 21.9\%،

23.5\%، 6.7\%، 2\% من إجمالى التكاليف

الثابتة البالغة نحو 14900 جنيه على النزتيب.

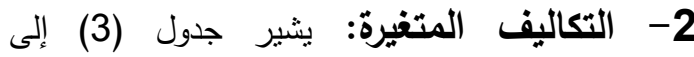
منوسطات التكاليف المتغيرة لفدان المورنجا بعينة البحث بمنطقة وادى النطرون خلال عام 2015/2014 حيث شملت تكاليف التشغيل لدورة إنتاج واحدة وهى تكاليف أجور العمالة، ومرتبات الإدارة، الري، التسميد والوقاية، جمع وتعبئة المحصول وكذلك تكلفة الصيانة الدورية. وقد بلغ متوسط تلك التك البنود نحو 1300،1000، 1850، 1000، 2500، 500 جنيه للفدان تمثل نحو 15.95، 12.27، 22.7، 12.27، 30.67، 6.13\% من إجمالى نكاليف التشغيل والبالغة نحو 8150 جنيه على التزتيب.
1- التكاليف الإستثمارية والثابتة: تنشير النتائج

الواردة بجدول (2) لمتوسط التكاليف الإستثمارية والثابتة والإهلاك السنوى لفدان المورنجا بعينة البحث بمنطقة وادى النطرون خلال عام 2015/2014، ومنه ينبين أن التكاليف النيف الإستثمارية تشمل كل من تكلفة إستصلاح الأرض

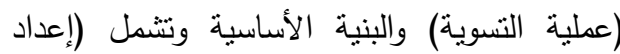
الطرق الداخلية، مبانى لإقامة العمال ومخازن لتخزين المستلزمات والأدوات). وبلغ متوسط نصيب الفدان نحو 1380 جنيه وبقسط إهلاك سنوي بلغ حوالي 70 جنيه. فى حين تضمنت التكاليف الثابتة تكلفة شبكة الري، تكلفة الزراعة عند التأسيس وتتثمل (تخطيط الأرض، أسمدة عضوية، أسدة معدنية، حفر وتجهيز وردم الجور بعد غرس الشتلات أو وضع البذور)، تكلفة الثتلات، تكلفة

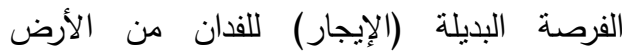

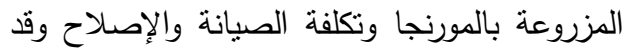

جدول (2): متوسطات التكاليف الإستثمارية والثابتة لفدان المورنجا بعينة البحث موسم إنتاج 2015/2014

\begin{tabular}{|c|c|c|}
\hline$\%$ & القيمة (جنيه ) & البيان \\
\hline 9.06 & 1350 & تكلفة الاستصلاح والبنية الأساسية \\
\hline 26.85 & 4000 & تكلفة شبكة الرى \\
\hline 31.88 & 4750 & تكلفة الزراعة (عند التاسيس) \\
\hline 23.49 & 3500 & تكلفة الشتلات \\
\hline 6.71 & 1000 & القيمة الإيجارية \\
\hline 2.01 & 300 & الصيانة والإصلاح \\
\hline 100 & 14900 & إجمالى التكاليف الإستتمارية والثابتة \\
\hline
\end{tabular}

المصدر : جمعت وحسبت من استمارة الاستبيان الخاصة بالدراسة الميدانية بمنطقة وادى النطرون موسم إنتاج 2015/2014. 
جدول (3): متوسطات تكاليف التشغيل لفدان المورنجا بعينة البحث موسم إنتاج 2015/2014

\begin{tabular}{|c|c|c|}
\hline$\%$ & القيمة (بالجنيه ) & تكاليف التشغيل \\
\hline 15.95 & 1300 & أجور العمال \\
\hline 12.27 & 1000 & مرتبات الإدارة والإثشراف \\
\hline 22.70 & 1850 & 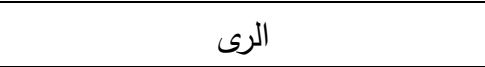 \\
\hline 12.27 & 1000 & التسميد والوقاية \\
\hline 30.67 & 2500 & تكلفة الحصاد والجمع وتعبئة المحصول \\
\hline 6.13 & 500 & تكلفة الصيانة الدورية \\
\hline 100 & 8150 & إجمالى تكاليف التشغيل \\
\hline
\end{tabular}

والتى يكون عندها حجم النشاط ممثلا بقيم أو وحدات

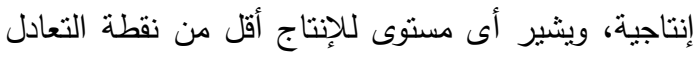

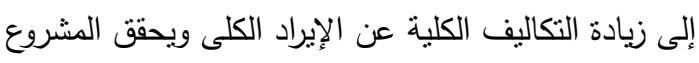

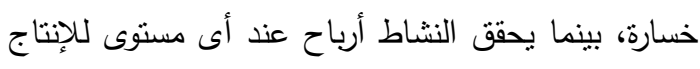

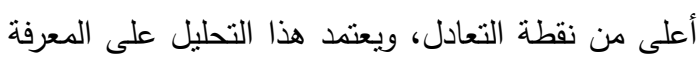

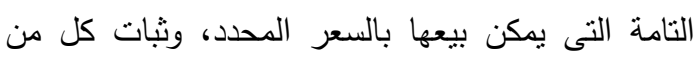

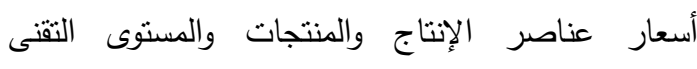

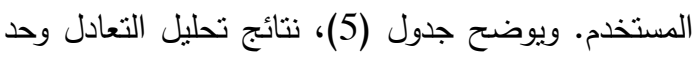
الأمان لإنتاج فدان مورنجا بعينة البحث موسم إنتاج 2015/2014، ومنه يتبين أن نقطة التعادل الكمى للفدان تقدر بحوالى 6.97، 141.8 كجم من البذور والأوراق على الترنيب.

وبمقارنتها بمستوى الإنتاج السنوي والبالغ حوالي 35، كوني

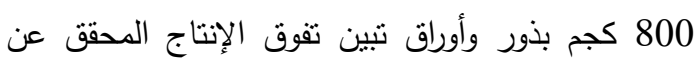

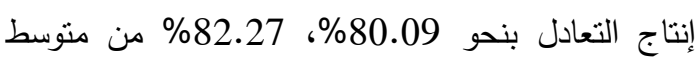
الإنتاج السنوي من البذور والأوراق لفدان المورنجا. وبتقدير

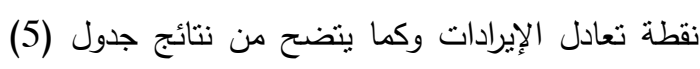
فقد بلغت حوالي 2440.63، 2410.8 جنيه، وبمقارنتها بمتوسط الإيراد السنوي والبالغ حوالي 12.25، 13.6 ألف 13.63

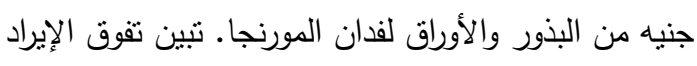

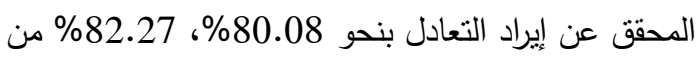
منوسط الإنتاج السنوي من البذور والأوراق لفدان المورنجا.
3- إيراد إنتاج المورنجا: يتضح من نتائج جدول (4) أن متوسط إيرادات إنتاج فدان المورنجا بعينة البحث

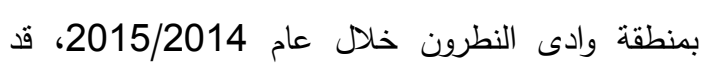

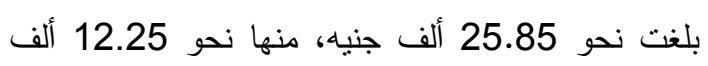
جنيه إيرادات إنتاج البذور، ونحو 13.6 ألف جنيه إيرادات

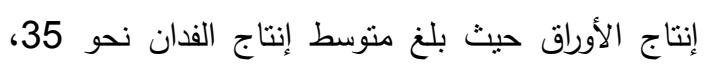

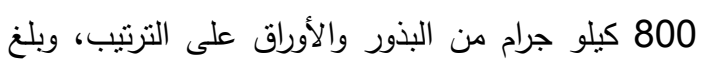

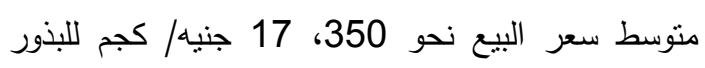

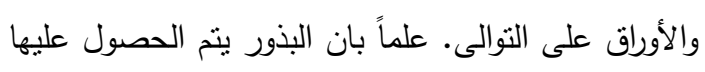

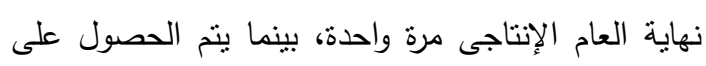

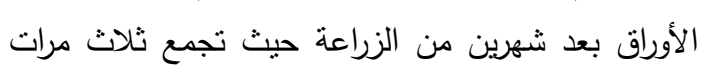
بين الجمعة والأخرى شهرين ثقريباً ثم تترك الأشجار لإنتاج

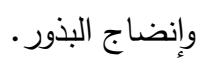

رابعاً: تحليل التعادل وحد الأمان لإنتاج المورنجا

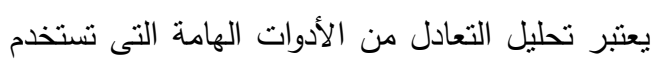

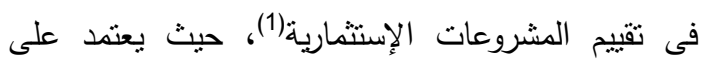

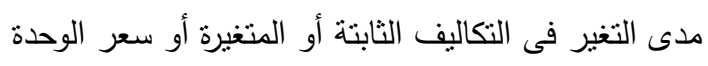

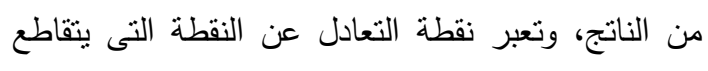
عندها منحنى الإيراد الكلى مع منحنى التكاليف الكلية لفية لفئل

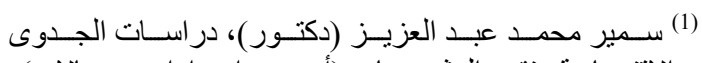

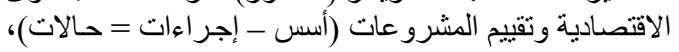
مؤسسة شباب الجامعة، الإسكندرية، 1987. 
جدول (4): متوسطات إيراد فدان المورنجا بعينة البحث موسم إنتاج 2015/2014

\begin{tabular}{|c|c|c|}
\hline القيمة أو الكمية & 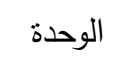 & 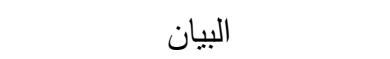 \\
\hline 35 & كيلو جرام & منوسط إنتاج الفدان من البذور \\
\hline 350 & جنيه & سعر الوحدة \\
\hline 800 & كيلو جرام & متوسط إنتاج الفدان من الأوراق \\
\hline 17 & جنيه & سعر الوحدة \\
\hline 25850 & جنيه & ال الإيراد \\
\hline
\end{tabular}

المصدر: جمعت وحسبت من استمارة الاستبيان الخاصة بالدراسة الميدانية بمنطقة وادى النطرون موسم إنتاج النياج

جدول (5): تحليل التعادل وحد الأمان لإنتاج فدان مورنجا بعينة البحث موسم إنتاج 2015/2014

\begin{tabular}{|c|c|c|}
\hline القيمة أو الكمية & 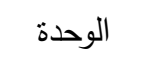 & البيان \\
\hline 38.81 & جنيه/ كجم & منوسط التكاليف المتغيرة للوحدة المنتجة من البذور \\
\hline 1.70 & جنيه/ كجم & منوسط التكاليف المتغيرة للوحدة المنتجة من الأوراق \\
\hline 2170 & جنيه & منوسط التكاليف الثابتة خلال العام \\
\hline 6.97 & كيلو جرام & نقطة التعادل الكمى 1 لإنتاج البذر \\
\hline 141.81 & كيلو جرام & نقطة التعادل الكمى 1 لإنتاج الأوراق \\
\hline 2440.63 & جنيه & نقطة إيرادات التعادل 2لإنتاج البنور \\
\hline 2410.78 & جنيه & نقطة إيرادات التعادل 2لإنتاج الأوراق \\
\hline 80.08 & $\%$ & حد الأمان الإنتاجى 3 لإنتاج البذور \\
\hline 82.27 & $\%$ & حد الأمان الإنتاجى 3 لإنتاج الأوراق \\
\hline 78.05 & $\%$ & حد الأمان السعرى 3لإنتاج البذر \\
\hline 84.93 & $\%$ & حد الأمان السعرى44إنتاج الأوراق \\
\hline 76.83 & جنيه & سعر التعادل 4لإنتاج البذر \\
\hline 2.56 & جنيه & سعر التعادل 5 لإنتاج الأوراق \\
\hline
\end{tabular}

1. نقطة التعادل الكمى= [التكاليف الثابتة للسنة /(سعر الوحدة المنتجة - متوسط التكاليف المتغيرة للوحدة المنتجة)] 2. نقطة إيرادات التعادل =[ التكاليف الثابتة للسنة الحالية/1- (متوسط النكاليف المتغيرة للوحدة الكنتجة/سعر الوحدة المنتجة)]

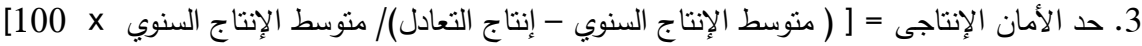

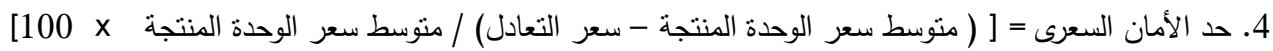
5. سعر التعادل = ( منوسط إجمالى التكاليف / منوسط إجمالى الإنتاج) المصدر: جمعت وحسبت من بيانات جداول 2، 3، 4. 


\section{An economic study for production of moringa crop in the new landes}

4- تم حساب القيمة الإيجارية للأرض بواقع 1000 جنيه

للفدان ونم احتسابها فى البنود الثابتة للمشروع.

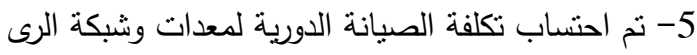

بمقدار ثابت طوال عمر المشروع، وينم إحلال شبكة

الرى وفقا للعمر الافتراضى المقدر لها 5 سنوات،

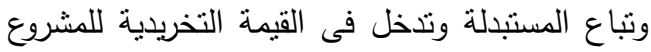

$$
\text { فى سنة الإحلال. }
$$

6- أسعار كل من المنتج وعناصر الإنتاج ثابتة خلال

$$
\text { عمر المشروع الافتراضى كما بجدول(1) بالملاحق. }
$$

7- نم تصميم جداول التدفقات النقدية الداخلة والخارجة

$$
\text { والصافية طوال عمر المشروع. }
$$

8- فى ضوء ما يمكن أن يتعرض له الإسنتمار فى المجال

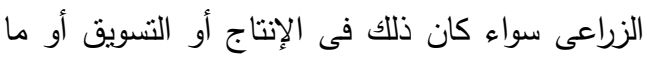

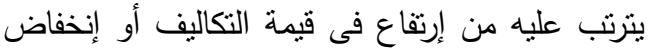

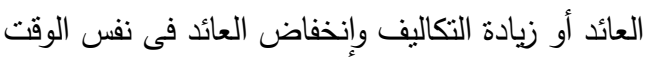

لذللك إعتمدت الدراسة على إستخدام أسلوب تحليل

الحساسية لقياس مدى حساسية المشروع لها.

\section{(1) معاييز التقييم المالى}

التشير نتائج جدول (6) إلى نتائج التحليل المالي لإنتاج

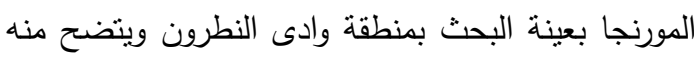

ما يلي: (1) بلغ صافى القيمة الحالية Net Present عند معدل الخصم 12\% Value (NPV) 75.97 ألف جنيه، مما يشير إلى جدوى الإستثمار فى مئ

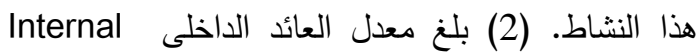
Rate return (IRR) الاقتراض لرأس المال والتى يمثلها سعر الفائدة التجاري

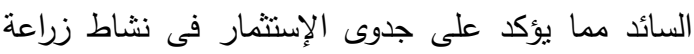

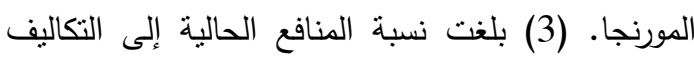
الحالية Benefit/ Cost Ratio (B/C) نحو 2.78 أى

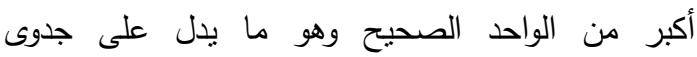
الإستثمار للمشروع. (4) بلغت فترة استرداد رأس المال Capital Pay Back (CPBP)
ويستخدم حد الأمان الإنتاجى لتقيبم حساسية المشروع

أمام انخفاض الطاقة الإنتاجية المدكن حدوثها بسبب الإنتاج

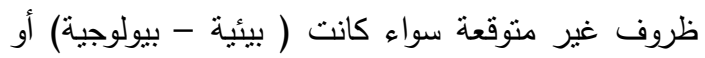
إقتصادية مثل إنخفاض الطاقة الإستيعابية للأسواق،

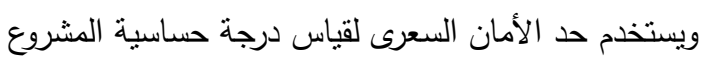
فى حال تعرض سعر الوحدة المنتجة للإنخفاض ومن ثم الثمان

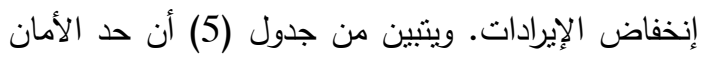
الإنتاجى قد بلغ نحو 80.08\%، 82.27\% من منوسط الإيراد الإنتاج السنوي من البذور والأوراق لفدان المورنجا. وهذا

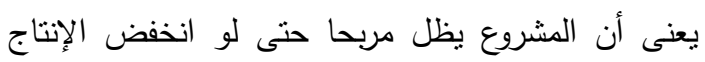

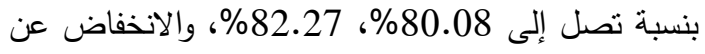

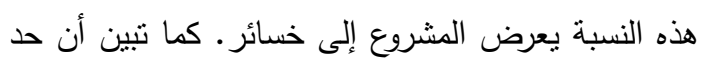

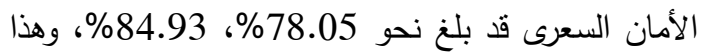
يعنى أن المشروع بظل مربحا حتى لو الخفض الستر بنسبة تصل إلى 18.05\%، 84.93\% لإنى الإنتاج البذور والأوراق وانخفاض السعر عن هذه النسبة يعرض المشروع لإلى

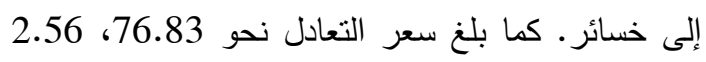

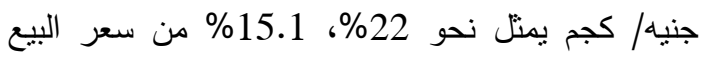
للبذور والأوراق على الترتيب.

\section{خامساً: التحليل المالي وتحليل الحساسية لإنتاج المورنجا}

إعتد التحليل المالي المستخدم للمعايير المخصومة

على عدد من الفروض تتفق مع المنطق الاقتصادى وهى:

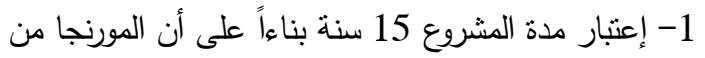
النباتات المعمرة والتى يزيد عمرها الإنتاجى عن 15 سنة.

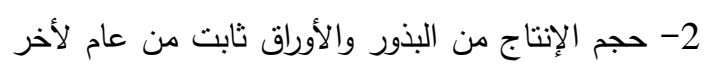

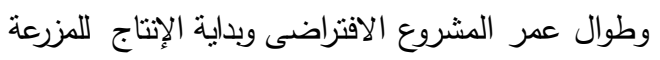

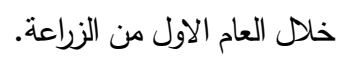

3- إستخدم سعر الخصم 12\% (السعر السائد على الفى لراعهات أذونات الخزانة من البنك المركزى) وهو يمثل أفضل

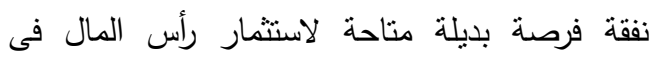

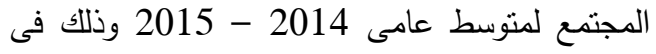
تقدير القيمة الحالية المستقبلية لكل من إيراد وتكاليف

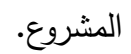


يثير إلى إمكانية إسترداد رأس المال الستثمر فى أقل من عامين. جدول (6): نتائج التحليل المالى لإنتاج المورنجا بعينة البحث بمنطقة وادى النطرون

\begin{tabular}{|c|c|c|c|c|}
\hline CPBP & $B / C$ & IRR & NPV & المعايير \\
\hline سنة & - & $\%$ & ألف جنيه & الوحدة \\
\hline 1.43 & 2.78 & 70 & 75.97 & القيمة \\
\hline
\end{tabular}

المصدر: نتائج تحليل بيانات جدول (1) بالملاحق باستخدام برنامج Cost Benefit Analysis.

الأسعار الاقتصادية، ويعتمد على نفس فروض التحليل المالى ولكن باستخدام الأسعار الاقتصادية.

معايير التقييم الاقتصادى: بإستخدام العلاقات الرياضية بين القيم الحالية للإيرادات والتكاليف نم تقدير معايير الثقييم الإقتصادى. وتتير نتائج جدول (8) إلى نتائج التحليل

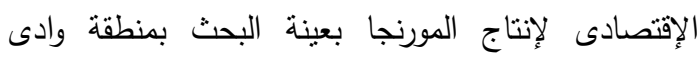
النطرون ويتضح منه ما يلي: (1) بلغت القيمة الحالية للقيمة المضافة نحو 137.30 ألف جنيه. (2) بلغت القيمة الحالية لصافى القيمة المضافة نحو 113.39 ألف جنيه.

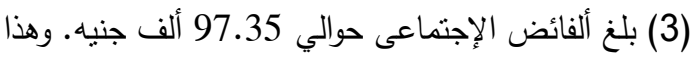
يشير إلى المساهمة الإيجابية لإنتاج المورنجا فى الاخل الإلى

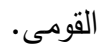

(2) تحليل الحساسية: ينضح من النتائج الواردة بجدول (7) أن مشروع إنتاج المورنجا بمنطقة وادى النطرون يمكن استمرار جدواه الاقتصادية فى ظل حدوث (1) زيادة تكاليف التشغيل مع التئن

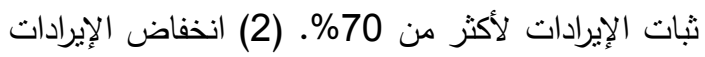

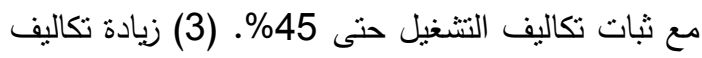
النتغيل وانخفاض الإيرادات معاً حتى 35\%. وتم الوصول لذلك بنحو 35 محاولة للحالات الثنلاث السابقة. سادساً: التحليل الإقتصادى لإنتاج المورنجا: يهدف التحليل الإقتصادى إلى تقدير مدى مساهمة المشروع فى الإنى تحقيق كافة الأهداف الأساسية للتتمية سواء كانت اقتصادية أو غير اقتصادية مع الأخذ فى الاعتبار الآثار

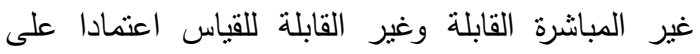

جدول (7): نتائج تحليل الحساسية لإنتاج المورنجا بعينة البحث بمنطقة وادى النطرون

\begin{tabular}{|c|c|c|c|c|}
\hline CPBP & $\mathrm{B} / \mathrm{C}$ & IRR & NPV & المعايير \\
\hline سنة & - & $\%$ & ألف جنيه & 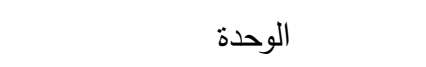 \\
\hline 3.17 & 1.54 & 32 & 30.5 & زيادة تكاليف التتشغيل 70\% \\
\hline 5.99 & 1.06 & 17 & 5.23 & انخفاض الإيرادات 45\% \\
\hline
\end{tabular}




\section{An economic study for production of moringa crop in the new landes}

\begin{tabular}{|l|l|l|l|l|}
\hline 7.77 & 1.33 & 13 & 1.06 & \%35 زيادة التكاليف وانخفاض العائد معاً \\
\hline
\end{tabular}

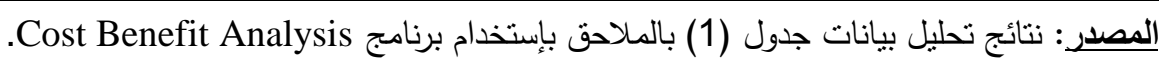

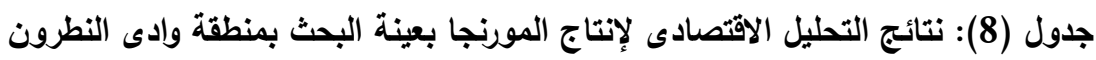

\begin{tabular}{|c|c|c|}
\hline 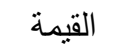 & 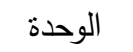 & معايير التحليل الاقتصادى \\
\hline 157.21 & ألف جنيه & إجمالى القيمة الحالية للإيرادات \\
\hline 23.91 & ألف جنيه & إجمالى القيمة الحالية للتكاليف الإستثمارية والثابتة \\
\hline 19.91 & ألف جنيه & إجمالى القيمة الحالية لمستلزمات الإنتاج \\
\hline 16.04 & ألف جنيه & إجمالى القيمة الحالية للأجور \\
\hline 137.30 & ألف جنيه & القيمة الحالية للقيمة المضافة1 \\
\hline 113.39 & ألف جنيه & القيمة الحالية لصافى القيمة المضافة2 \\
\hline 97.35 & ألف جنيه & الفائض الاجتماعى3 3 \\
\hline
\end{tabular}

1. القيمة الحالية للقيمة المضافة= إجمالى القيمة الحالية للإيرادات - إجمالى القيمة الحالية لمستلزمات الإنتاج. 2. القيمة الحالية لصافى القيمة المضافة= القيمة الحالية للقيمة المضافة - إجمالى القيمة الحالية للتكاليف الإستثمارية والثابتة. 3. الفائض الإجتماعى = القيمة الحالية لصافى القيمة المضافة - إجمالى القيمة الحالية للأجور. المصدر: حسبت من نتائج تحليل بيانات جدول (2) بالملاحق بإستخدام برنامج Cost Benefit Analysis.

المورنجا والإستفادة من نواتج العصر سواء فى تصنيع

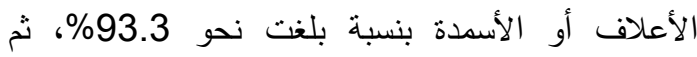
مشكلة عدم وجود مصادر موثوق بها للحصول على الثتلات ويعانى منها نحو 86.7\%، وأخيراً مشكلة عدم توافر العمالة الددربة وإرتفاع أجرها بنسبة بلغت نحو .$\% 80$

وقد طالب المنتجين بضرورة إهتمام الجهات المختصة بالعمل على الترويج لمحصول المورنجا من خلال نوضيح

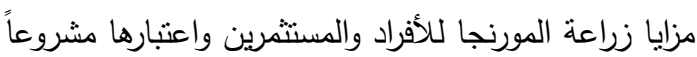
قومياً. والعمل على فتح اسواق داخلية وخارجية لدنتجات
سابعاً: المشكلات التى تواجة منتجى المورنجا بعينة الاراسة: نثير نتائج جدول (9) إلى الأهمية النسبية للمشكلات التى نواجة منتجى المورنجا بمنطقة وادى

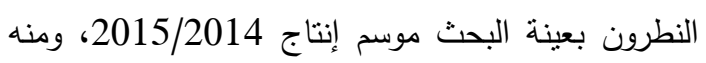
يتبين أن مشكلة صعوبة تسويق الإنتاج وإحتكار التجار ثأنى فى المرنبة الاولى بنسبة 100\% حيث أكد المنتجين على إحتكار مندوبي شركات تعبئة اوراق المورنجا للسعر وشروط النسليم، يليها مشكلة عدم وجود مصانع لنتنجات المورنجا بالمنطقة سواء لتجفيف وتعبئة الأوراق، أو معاصر لإستخلاص زيت المورنجا ومستخلص أوراق 


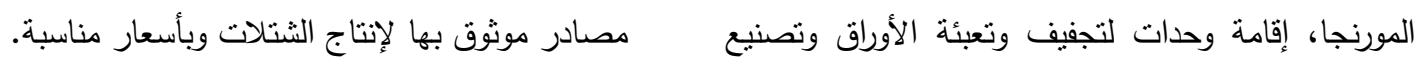
زيت المورنجا والاستفادة من مخلفات العصر، توفير

جدول (9): الأهمية النسبية للمشكلات التى تواجة منتجى المورنجا بعينة البحث موسم إنتاج 2015/2014

\begin{tabular}{|c|c|c|c|}
\hline$\%$ & 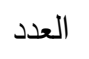 & 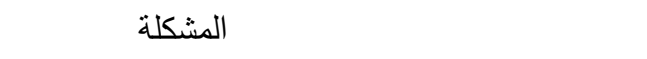 & 5 \\
\hline 100 & 15 & صعوبة تسويق الإنتاج وإحتكار التجار & 1 \\
\hline 93.33 & 14 & عدم وجود مصانع لمنتجات المورنجا من أوراق وبذور & 2 \\
\hline 86.67 & 13 & عدم وجود مصادر موثوق بها للبذور ولإنتاج الثتلات & 3 \\
\hline 80 & 12 & عدم توافر العمالة المدربة وإرتفاع أجرها & 4 \\
\hline
\end{tabular}

المصدر: جمعت وحسبت من استمارة الاستبيان الخاصة بالدراسة الميدانية بمنطقة وادى النطرون موسم إنتاج

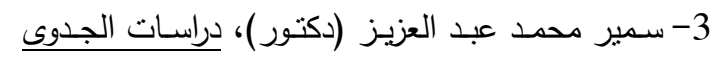

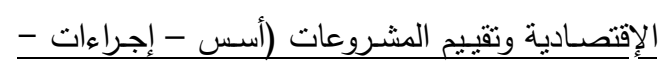

حالات)، مؤسسة شباب الجامعة، البحيرة، 1987.

4- محمد خالد بن حسين، المورنجا الثجرة المعجزة غذاء

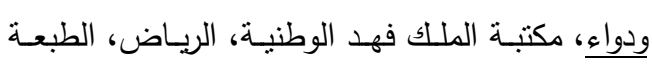

$$
\text { الأولى، } 2012
$$

5- المركز القـومى للبحـوث، الجمعيـة العلميـة المصـرية

للمورنجا، إحصاءات 2015، بيانات غير منشورة.

6- المركز القومى للبحـوث، الجمعيـة العلميـة المصـرية

للمورنجا، "الثجرة المعجزة- صديقة ألفقراء- استتمار

$$
\text { الأغنباء" نشرة رقم } 1 \text { لسنة } 2015 .
$$

7-وزارة الزراعـة واستصــلاح الأراضـي، الإدارة المركزيـة

للإرشاد الزراعي، "المورنجا دواء من الطبيعة" نشرة رقم

$$
1360 \text { لسنة } 2013 .
$$

8- وزارة الزراعـة واستصــلاح الأراضـي، الإدارة الزراعيـة

بوادي النطرون، قسم الإحصاء، بيانات غير منشورة .2015

9- Development potential for Moringa products, October 29th - November 2nd, 2001, Dar es Salaam, Tanzania.

10- Gittinger, J. Price,1982. "Economic Analysis of Agricultural projects", $2^{\text {nd }}$ edition, The johns Hopkins University press, Baltimore and London.

11- Brown Maxwell L, 1979. "Farm Budgets:" From Farm Income Analysis to
التوصيات : فى ضوء النتائج البحثية التى تم التوصل إليها توصى الدراسة بما يلى : (1) التركيز على الإهنمام بزراعة

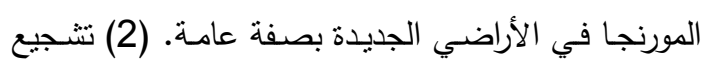
الـزراع وشـباب الخـريجين والمسـتنمرين على زراعـة هـذا المحصـول وذلك بتعريفهم بالأهميـة الاقتصـادية لزراعته. (3) تـوفير الثـتلات مـن مصـادر موثـوق بهـا وتسـويق

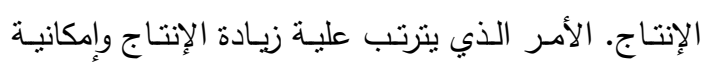

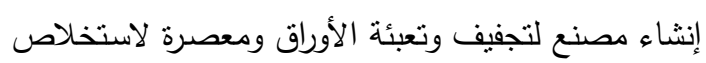

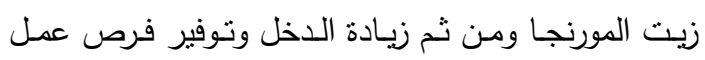

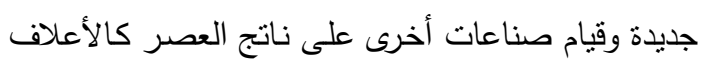

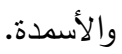

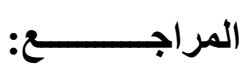

1- احمـد محمــ فـرج قاسـم، غـادة صـالح حسـن صـالح، محمـد فـوزي محمـد الدناصـورى (دكـاترة)، "التحليـلـ

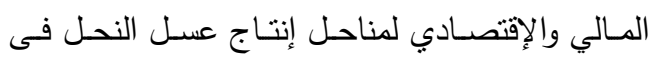
محافظة الإسكندرية"،مجلة المنوفية للبحوث الزراعية، مجلد 38، العدد 1 (الجزء الثاني)، فبراير 2013.

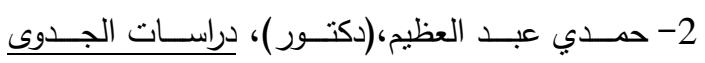
الاقتصـادية وتقيم المشـروعات، دار الثـروق، القاهرة، .1999 
12- World Bank, The economics of project analysis, Washington d.c. 1991, p 22.
Agricultural projects Analysis" Baltimore, Md, Johns Hopkins University Press.

جدول (1): متوسط التكاليف والإيرادات لمزارع إنتاج المورنجا بالأسعار الجارية بالجنيه خلال العمر الافتراضى للمشروع بعينة البحث بمنطقة وادى النطرون

\begin{tabular}{|c|c|c|c|c|c|c|}
\hline إلجمالى الإيرادات & إجمالى التكاليف & التشاليف & والإصلاح & الإيجار & الإنتاليف & / / / لبنوات / / / / \\
\hline 0 & 23050 & 8150 & 300 & 1000 & 13600 & 0 \\
\hline 25850 & 9450 & 8150 & 300 & 1000 & 0 & 1 \\
\hline 25850 & 9450 & 8150 & 300 & 1000 & 0 & 2 \\
\hline 25850 & 9450 & 8150 & 300 & 1000 & 0 & 3 \\
\hline 25850 & 9450 & 8150 & 300 & 1000 & 0 & 4 \\
\hline $26050^{(5)}$ & 9150 & 8150 & $500^{(3)}$ & 1000 & $4000^{(1)}$ & 5 \\
\hline 25850 & 9450 & 8150 & 300 & 1000 & $500^{(2)}$ & 6 \\
\hline 25850 & 9450 & 8150 & 300 & 1000 & 0 & 7 \\
\hline 25850 & 9450 & 8150 & 300 & 1000 & 0 & 8 \\
\hline 25850 & 9450 & 8150 & 300 & 1000 & 0 & 9 \\
\hline $26050^{(6)}$ & 13150 & 8150 & $500^{(4)}$ & 1000 & 4000 & 10 \\
\hline 25850 & 9450 & 8150 & 300 & 1000 & 0 & 11 \\
\hline 25850 & 9450 & 8150 & 300 & 1000 & 0 & 12 \\
\hline 25850 & 9450 & 8150 & 300 & 1000 & 0 & 13 \\
\hline 25850 & 9450 & 8150 & 300 & 1000 & $1000^{(2)}$ & 14 \\
\hline $28350^{(7)}$ & 9450 & 8150 & 300 & 1000 & 0 & 15 \\
\hline
\end{tabular}


(1) قيمة إحلال شبكة الرى. (2) نصيب الفدان فى ماكينة الرى. (3) نصيب الفدان فى عمرة ماكينة الرى. (4) نصيب الفدان فى تجليد شبكة الرى.

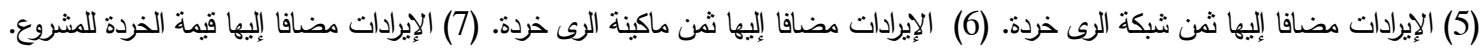
المصدر: جمعت وحسبت من إستمارات الإستيان لعينة البحث الميداني. جدول (2): متوسط التكاليف والإيرادات لمزارع إنتاج المورنجا بالأسعار الاقتصادية بالجنيه خلال العمر الافتراضي للمشروع بعينة البحث بمنطقة وادى النطرون

\begin{tabular}{|c|c|c|c|c|c|c|}
\hline إل إلجمالى & إلتكمالى اليف & التشاليف & والصيانة & الإيجار & الإنتاليف & السنوات / البيان \\
\hline 0 & 22662.80 & 8150 & 300 & 1000 & 13212.80 & 0 \\
\hline 25850 & 9450 & 8150 & 300 & 1000 & 0 & 1 \\
\hline 25850 & 9450 & 8150 & 300 & 1000 & 0 & 2 \\
\hline 25850 & 9450 & 8150 & 300 & 1000 & 0 & 3 \\
\hline 25850 & 9450 & 8150 & 300 & 1000 & 0 & 4 \\
\hline 26050 & 13100 & 8150 & 500 & 1000 & 3450 & 5 \\
\hline 25850 & 9950 & 8150 & 300 & 1000 & 500 & 6 \\
\hline 25850 & 9450 & 8150 & 300 & 1000 & 0 & 7 \\
\hline 25850 & 9450 & 8150 & 300 & 1000 & 0 & 8 \\
\hline 25850 & 9450 & 8150 & 300 & 1000 & 0 & 9 \\
\hline 26050 & 13100 & 8150 & 500 & 1000 & 3450 & 10 \\
\hline 25850 & 9450 & 8150 & 300 & 1000 & 0 & 11 \\
\hline 25850 & 9450 & 8150 & 300 & 1000 & 0 & 12 \\
\hline 25850 & 9450 & 8150 & 300 & 1000 & 0 & 13 \\
\hline 25850 & 10330 & 8150 & 300 & 1000 & 880 & 14 \\
\hline 28350 & 9450 & 8150 & 300 & 1000 & 0 & 15 \\
\hline
\end{tabular}




\title{
An economic study for production of moringa crop in the new landes
}

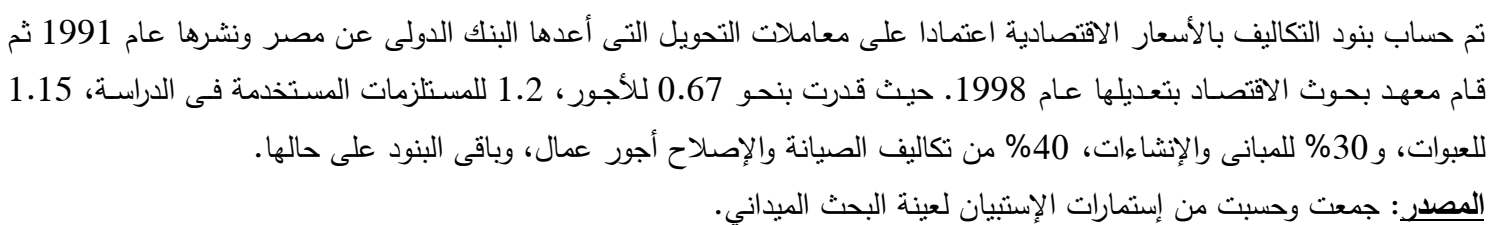

\section{AN ECONOMIC STUDY FOR PRODUCTION OF MORINGA CROP IN THE NEW LANDES}

\author{
M. A. Abo Elnaga \\ Department of Economic Studies, Division of Economic and Social Studies, \\ Desert Research Center, Egypt.
}

\begin{abstract}
This study is preformed to investigate on: (1) Reveal the economic aspects of Moringa crop production projects such as costs and revenues. (2) Determine the quantitative break even point of the total costs and returns. (3) Study the financial and economical analysis of Moringa crop production projects.

The main results of the study can be summarized as:

(1) high economic efficiency of Moringa crop production projects.

(2) investment in the production of Moringa lucrative projects under the discount rate of $11 \%$ based on the internal rate of return of $70 \%$, which indicates that the pound invested in the production of Moringa generates about L.E 1.87.

(3) the ability of Moringa production activity on the face of the changes that occur in both revenue and costs based on the sensitivity analysis .

(4) Activity bring Moringa production yields more than the costs used in the production based on the net value added.

(5) positive contribution to the production of Moringa in national income due to the high valueadded compared to net wage based on the Social surplus.

Conclusively, the study concluded with several recommendations, mainly to encourage farmers and young graduates and investors on the cultivation of this crop and it introduced them the economic importance of cultivation Moringa to provide seedlings from reliable sources and marketing of production, which would result in increased production and the possibility of establishing a factory to extract the Leaves and Seed, Moringa and then increase income and create new jobs and do other industries on the outcome of the times feeds and fertilizers.
\end{abstract}

Key words: Moringa crop, costs, return, financial analysis, economical analysis, New Lands, Netron Valley. 